\title{
PENGARUH KUALITAS PELAYANAN FRONT LINER TERHADAP KEPUASAN NASABAH PERBANKAN SYARIAH DI BANK MUAMALAT CABANG PALANGKA RAYA
}

\section{Influence of Front Liner service quality to customer satisfaction of Syariah banking} in Bank Muamalat Palangka Raya Branch

\section{Farid Zaky Yopiannor* Nur Yasin}

Universitas Muhammadiyah Palangkaraya, Palangka Raya Central Kalimantan, Indonesia

email:

farid.zaky@umpalangkaraya.ac.id

\section{Kata Kunci:}

Kualitas Pelayanan

Kepuasan

Nasabah

\section{Keywords:}

Service Quality

Satisfaction

Customer

\section{Accepted}

June 2016

\section{Published}

Oktober 2016

\begin{abstract}
Abstrak
Tujuan penelitian ini bertujuan untuk mengetahui seberapa besar pengaruh kualitas pelayanan Front Liner terhadap kepuasan nasabah Bank Muamalat Cabang Palangka Raya. Metode yang digunakan dalam penelitian ini adalah metode Kuantitatif, Tehnik pengumpulan data menggunakan Angket (kuesioner), jumlah sampel dalam penelitian ini adalah sebanyak 345 Nasabah Bank Muamalat yang ada di Palangka Raya. Tehnik Pengambilan sampel adalah dengan cara tehnik random sampling atau sampel acak, Tehnik análisis yang digunakan untuk mengolah data yaitu dengan tehnik análisis regresi liniear sederhana.
\end{abstract}

Hasil análisis dengan menggunakan regresi liniear sederhana di dapat persamaan regresi $(Y=a+b X)$, telah diketahui $Y=26.885+0.205 X$, maka ada pengaruh kualitas pelayanan terhadap kepuasaannasabah Bank Muamalat di Kota Palangka Raya.

\section{PENDAHULUAN}

Dengan kehadiran Bank Syariah yang lain, Bank Muamalat Cabang Palangka Raya bersaing juga dalam hal pelayanan, karena kepuasan pelanggan terhadap pelayanan sangat berkaitan terhadap suatu dorongan kepada pelanggan untuk menjalin ikatan yang kuat dengan perusahaan. Upaya peningkatan kualitas pelayanan oleh bank Muamalat Cabang Palangka Raya selalu berusaha untuk menemukan cara-cara yang berorientasi pada kepuasan nasabah. Namun masih muncul keluhan-keluhan dari nasabah yang belum merasakan kepuasan dalam hal pelayanan, seperti dalam jeda waktu pelayanan teler antara satu dengan yang lain terlalu lama, sebagian nasabah belum merasakan kenyamanan dalam hal pelayanantersebut.

Menurut Zeithaml et.al (Laksana, 2008:88) kualitas pelayanan dapat didefenisikan bahwa kulitas pelayanan yang diterima konsumen dinyatakan besarnya penrbedaan antara harapan atau keinginan konsumen dengan tingkatpersepsi.

Kepuasan Pelanggan/Nasabah

Menurut Kotler (Sangadji dan Sopiah, 2013:18I) Kepuasan pelanggan diukur dengan seberapa besar harapan pelanggan tentang produk dan layanan sesuai dengan kinerja produk dan pelayanan yang aktual. 
Kepuasan pelanggan adalah perasaan senang atau kecewa yang muncul setelah membandingkan persepsi atau kesan dengan kinerja suatu produk atau jasa dan harapan-harapannya.

Hipotesis

Ho (Hipotesisi nihil) yaitu Hipotesis yang menyatakan tidak adapengaruh antara variable dengan variablelain.

$\mathrm{Ha}$ (Hipotesisi alternatif) yaitu Hipotesis yang menyatakan adanyapengaruh antara variable dengan variablelain.

\section{METODOLOGI}

Tipe penelitian ini merupakan penelitian diskriptif kuantitatif yaitu penelitian tentang data yang dikumpulkan dan dinyatakan dalam bentuk angkaangka, meskipun juga berupa data kualitatif sebagai pendukungnya, seperti kata-kata atau kalimat yang tersusun dalam angket, kalimat thasil konsultasi atau wawancara antara peneliti daninforman.

\section{HASIL DAN PEMBAHASAN}

Melalui data deskripsi pengaruh kualitas pelayanan front linerBank Muamalat di Palangka Raya berada dikatagori yang Puas dengan persentase 52,17\% kategori Cukup Puas $47.54 \%$, dan kategori Tidak Puas sebesar $0.29 \%$ $\mathrm{Hal}$ ini mengindikasikan bahwa pengaruh kualitas pelayanan front liner bank muamalat di palangkaraya berada dikategori Puas. Kemudian dilihat dari variabel kepuasan nasabah bank muamalat palangkaraya berada pada kategori Puas 46,09\%, kategori Cukup Puas sebesar 53,33\%, dan kategori Tidak Puas sebesar 0,58\%. Ini membuktikan bahwa kepuasan nasabah bank Muamalat berada pada Kategori Cukup Puas

Berdasarkan perhitungan nilai rata-rata dari standar devation ideal di atas, kepuasan nasabah dengan pelayanan front liner berada pada posisi Puas dengan angka selisih persentase(\%) yaitu 52, I7\% dan 46,09\% Ini membukatikan adanya pengaruh yang signifikan antara pelayanan Publik dankepuasan.

Hasil Analisis regresi bantuan program SPSS maka di peroleh nilai $a=26,885$ dan $b=0,2050$ apabila hasil perhitungan a dan $b$ dimasukan kedalam regresi linier sederhana maka sebagai berikut : $Y=26,885+$ $0,2050 \times$.

Dengan demikian hipotesis yang berbunyi ada pengaruh kualitas pelayanan front linerterhadap kepuasana nasabah dibank muamalat cabang palangka raya , dapat di buktikan kebenarannya dengan diperoleh niali a dan b di atas.

Adanya pengaruh Kualitas Pelayanan front liner dengan kepuasan Nasabah Bank Muamalat Cabang Palangka Raya , berdasarkan hasil pengolahan data secara stastistik dari beberapa indikator yang telah di diskripsikan sebelumnnya , indikator Kualitas Pelayanan Front Liner berpengaruh terhadap kepuasan nasabah. dapat dibuktikan kebenaranya dilihat dari indikator Tangibles (kemudahan) berpengaruh terhadap fisik, perlengkapan, pegawai, dan sarana komunikasi sedangkan Emotional Faktor berpengaruh terhadap system antrian dan syarat ketentuan.

Berdasarkan hasil penelitian dengan menggunakan rumus Regresi Linier Sederhana dan Program SPSS, dihasilkan regresi $Y=26,885+0,2050 X$, dari analisis data dapat disimpulkan bahwa ada pengaruh antara kualitas pelayanan front liner terhadap kepuasan nasabah di Bank Muamalat Cabang Palangka Raya. Adanya pengaruh Kualitas Pelayanan front liner dengan kepuasan Nasabah Bank Muamalat Cabang Palangka Raya , berdasarkan hasil pengolahan data secara stastistik dari beberapa indikator yang telah di diskripsikan sebelumnnya, indikator Kualitas Pelayanan Front Liner berpengaruh terhadap kepuasan nasabah, dapat dibuktikan kebenaranya di lihat dari indikator Realiability, Responsivenes, Asurance, dan Empaty 
berpengaruh terhadap kualitas pelayanan, dan indikator kualitas produk, Service Quality, harga dan biaya berpengaruh terhadap kepuasan nasabah. Untuk indikator Tangibel (kemudahan) dan Emotional Factor masih adanya nasabah yang merasakan ketidakpuasan.

Dari beberapa indikator telah diketahui bahwa indikator Kualitas Pelayanan berupa Tangibel, Realiability, Responsivenes, Asurance, dan Empaty responden menjawab Cukup. Sedangkan Indikator Kepuasan Nasabah berupa Kualitas Produk, Service quality, emotional factor, Harga dan biaya menjawab Puas. Hal Ini dapat dibuktikan bahwa semakin baik atau meningkatnnya pelayanan yang telah diberikan Bank Muamalat maka semakin tinggi juga tingkat Kepuasan Nasabah tersebut.

\section{KESIMPULAN}

Berdasarkan hasil penelitian yang telah dilakukan, analisis data dapat disimpulkan bahwa ada pengaruh antara kualitas pelayanan front liner terhadap kepuasan nasabah di Bank Muamalat Cabang Palangka Raya. Adanya pengaruh Kualitas Pelayanan front liner dengan kepuasan Nasabah Bank Muamalat Cabang Palangka Raya , berdasarkan hasil pengolahan data secara stastistik dari beberapa indikator yang telah di diskripsikan sebelumnnya, indikator Kualitas Pelayanan Front Liner berpengaruh terhadap kepuasan nasabah, dapat dibuktikan kebenaranya di lihat dari indikator Realiability, Responsivenes, Asurance, dan Empaty berpengaruh terhadap kualitas pelayanan, dan indikator kualitas produk, Service Quality, harga dan biaya berpengaruh terhadap kepuasan nasabah. Untuk indikator Tangibel (kemudahan) dan Emotional Factor masih adanya nasabah yang merasakan ketidakpuasan.

Sehingga diharapkan kepada Bank Muamalat agar dapat meningkatkan pelayanannya dalam melayani nasabah bank dalam hal ,kemudahan (Tangibel), kehandalan (Realiability), Ketanggapan (Responsivenes), jaminan (Asurance), dan kepedulian(Empaty). Dan diharapkan juga kepada karyawan Bank Muamalat khususnya front Liner dapat lebih meningkatkan perannya dalam Kualitas Produk, Service quality, emotional factor, Harga, dan Biaya, agar nasabah merasa sangat puas.

\section{REFERENSI}

Adya,Atya.2004. Dasar-Dasar Pelayanan Prima. Jakarta: PT. Elex Media Komputindo.

Chandra, Gregorius. 2012. Service, Quality \& Satisfaction Edisi 3,Yogyakarta:CV Andi Offset.

Endriani, S. 2015. Konsep Uang: Ekonomi Islam VS Ekonomi Konvensional. Anterior Jurnal, I5(I), 70-75.

Hardiyansyah. 20II. Kualitas Pelayanan Publik. Yogyakarta : Gava Media

Irwan, Juwand. 2004. Kepuasan Pelayanan. Jakarta : Erlangga.

Juniarso Ridwan dan Achmad Sodik Sudrajat. 2010 Hukum Administrasi Negara dan Kebijakan Pelayanan Publik. Bandung: Penerbit Nuansa.

Laksana, Fajar. 2008. Manajemen Pemasaran. Yogyakarta: Graha IImu.

Lupiyoadi Rambat, 2006. Manajemen Pemasaran Jasa, Jakarta: CV Salemba.

Mahmudi. 20I0. Manajemen Kinerja Sektor Publik, Edisi. kedua. Sekolah Tinggi IImu Manajemen YKPN. Yogyakarta.

M,Nasir. 2003. Metode Penelitian. Jakarta: Galia Indonesia.

Nasution M.N. 2004. Manajemen Jasa Terpad. Bogor:Ghalia Indonesia. 
Pasolong, Harbani. 20II. Teori Administrasi Publik. Bandung: Alfabeta.

Ratminto \& Atik Septi Winarsih. 2007. Manajemen Pelayanan. Yogyakarta: Pustaka Pelajar

Sangadji, Etta Mamang dan Sopiah. 2013. Prilaku Konsumen. Yogyakarta: CV Andi Offset.

Sinambela, Lijan Poltak. 20I0. Reformasi Pelayanan Publik ,teori, kebijakan dan Implementasi. Jakarta. PT Bumi Aksara

Sugiyono. 2002. Metode Penelitian. Bandung: Alpabeta.

Tjiptono, Fandy. 2006. Manajemen Jasa. Yogyakarta: CV Andi Offset. 